\title{
Diagnosing urinary tract abnormalities: intravenous urography or CT urography?
}

This article was published in the following Dove Press journal:

Reports in Medical Imaging

7 April 2014

Number of times this article has been viewed

\section{Mohamed Abou El-Ghar \\ Huda Refaie \\ Doaa Sharaf \\ Tarek El-Diasty}

Radiology Department, Urology and Nephrology Center, Mansoura University, Mansoura, Egypt
Correspondence: Mohamed Abou

\section{El-Ghar}

Radiology Department, Urology

and Nephrology Center, Mansoura

University, 72 El-Gomhoria Street,

Mansoura, Egypt 35516

Tel +20 502262222

Email maboelghar@mans.edu.eg
Abstract: For many years, intravenous urography (IVU) was the modality of choice for diagnosing urinary tract abnormalities. IVU has many drawbacks including poor diagnostic accuracy in diagnosis and characterization of parenchymal lesions, also in cases of nonfunctioning kidneys. It has little diagnostic role to detect the cause of obstruction in absence of radio-opaque stones along the course of the urinary tract (UT). In the last two decades, with the era of the computed tomography (CT), CT has become the gold standard for diagnosis of urinary stones, while multiphasic CT urography (CTU) has become the most useful diagnostic tool in different UT abnormalities including complex congenital anomalies, trauma, infection and tumors. Also, the "one-stop-shop" use of CTU in different anomalies including vascular, parenchymal, and urothelial evaluation has a great impact in management of patients. CT has many disadvantages over IVU including its high cost and the higher radiation dose but it is more effective than IVU.

Keywords: CTU, IVU, urinary tract, obstruction, tumor, congenital

During the last 80 years, intravenous urography (IVU) has played a major role in the work-up of diseases in the kidneys and the upper urinary tract. IVU was the "queen" of procedures in the morphologic examination of urological diseases such as congenital malformations, renal colic, and follow-up of surgery, but it has been gradually replaced in recent years as the "gold standard" of investigation of the renal parenchyma and urinary tract. Modern cross-sectional modalities have shown that IVU does not fulfill current requirements and that patients with renal colic are better examined by nonenhanced computed tomography (CT) scanning, as this method finds more stones (100\% versus $60 \%){ }^{1}$ Furthermore, a disease outside the upper urinary tract is found in about $15 \%$ of patients with renal colic, and in 3\%, another kidney or upper urinary tract disease is found. For patients with hematuria, CT urography (CTU) is a better alternative, as it combines the advantages of CT with those of IVU. IVU misses about $15 \%$ of renal tumors larger than $3 \mathrm{~cm}$ in diameter and almost all smaller than $3 \mathrm{~cm}$. In 1995, Smith et $\mathrm{al}^{2}$ published the results of an early study evaluating the findings of both nonenhanced CT and IVU in 20 patients with acute flank pain. Of the twelve patients found to have obstruction on both modalities, five had a ureteric stone that was demonstrated on both nonenhanced CT scans and IVU radiographs, six had a stone that was depicted on nonenhanced CT scans only, and in one patient, a stone could not be detected by either modality. ${ }^{1,3}$

IVU has been gradually replaced over recent years as the "gold standard" method of investigation for the renal parenchyma and urinary tract by two new modalities, ultrasound and computed tomography. The advantages of CT are clearly established, including that contrast resolution allows the detection of almost all stones except for 
certain complications of triple-combination therapy in HIVseropositive patients, extensive cover-facilitating identification of differential diagnoses, rapidity, greater efficacy, and finally, the absence of risk related to the injection of iodinated contrast agents in this indication. However, the performance of CT may be more limited in certain situations, such as in thin patients or when the female genital tract also needs to be investigated. However, IVU is not more contributive in this context. The current place of IVU in renal colic is, therefore, to establish a definitive diagnosis, to guide an urgent procedure (removal of an obstruction in the context of infection) when CT is unavailable, or to avoid excessive irradiation, as in pregnant women, when ultrasound or even magnetic resonance imaging and magnetic resonance urography have not been sufficiently contributive. However, in the absence of IVU, we may fail to diagnose papillary necrosis. IVU is an examination of the past, without a future indeed, but with a descendant: CTU. ${ }^{4}$

\section{CTU or IVU in different urinary tract abnormalities \\ Anatomical variants and pseudo tumors}

Anatomical variants include many subtypes such as ectopic kidney, either simple or crossed (Figure 1). In crossed ectopia, the kidneys may be fused. IVU can detect kidney position if kidney function is adequate, but in the case of kidney fusion, IVU cannot determine whether the kidneys are fused or not (Figure 2).

CTU can detect actual kidney location and fusion better than IVU, and it is also better for the detection of kidney duplication, especially in the case of a nonfunctioning moiety. CTU can detect associated anomalies with duplication, such as ectopic insertion with the actual site of insertion, and it also can detect associated ureterocele. Ureterocele appears as a round or oval filling defect related to ureteric insertion at CTU and IVU. In cases of parenchymal pseudotumors, CT can
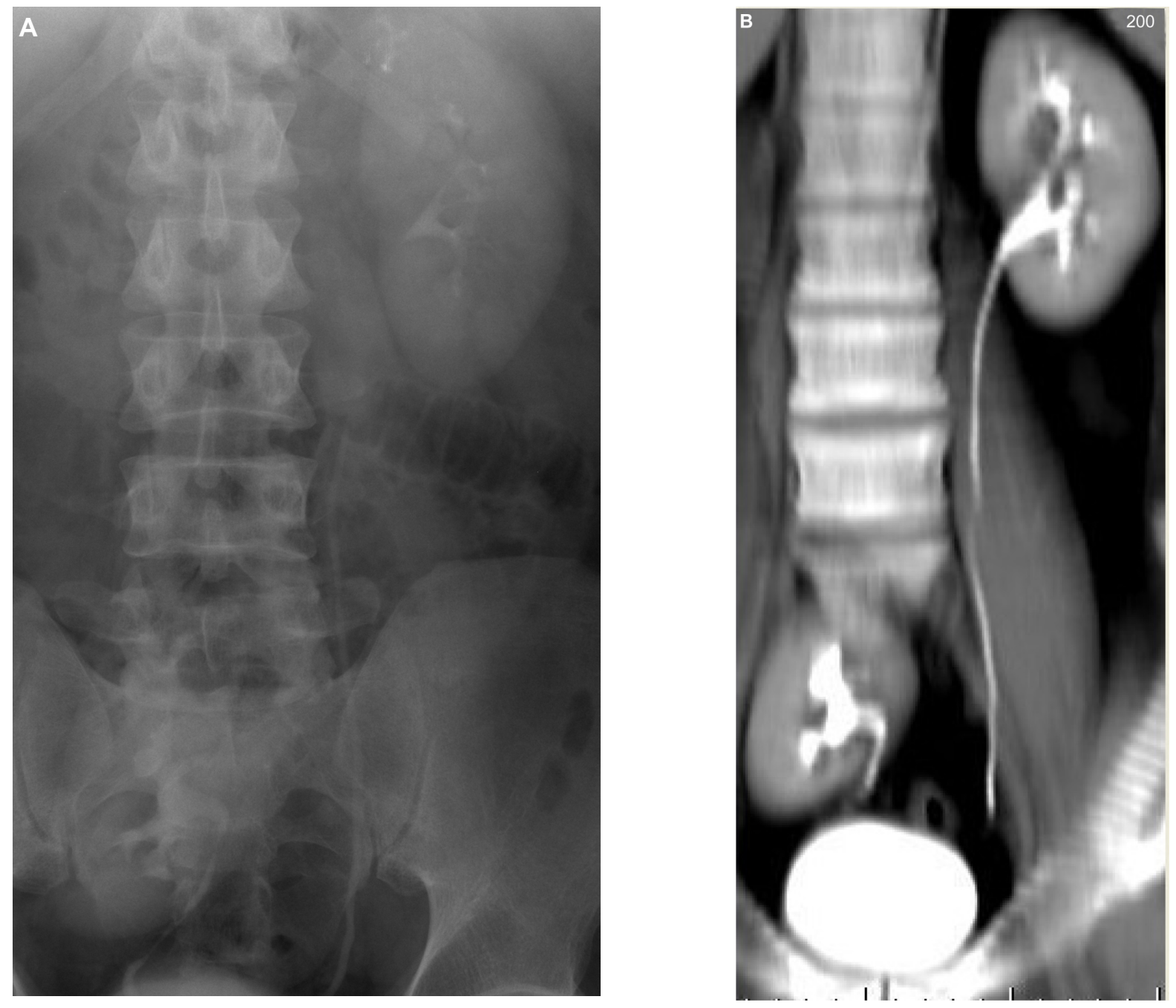

Figure I Ectopic pelvic right kidney. Intravenous urography $(\mathbf{A})$ and computed tomography urography $(\mathbf{B})$ both show the right kidney at the pelvic region with adequate excretory function and normal calyceal configuration. Computed tomography urography shows better adequate visualization of the renal parenchyma. 

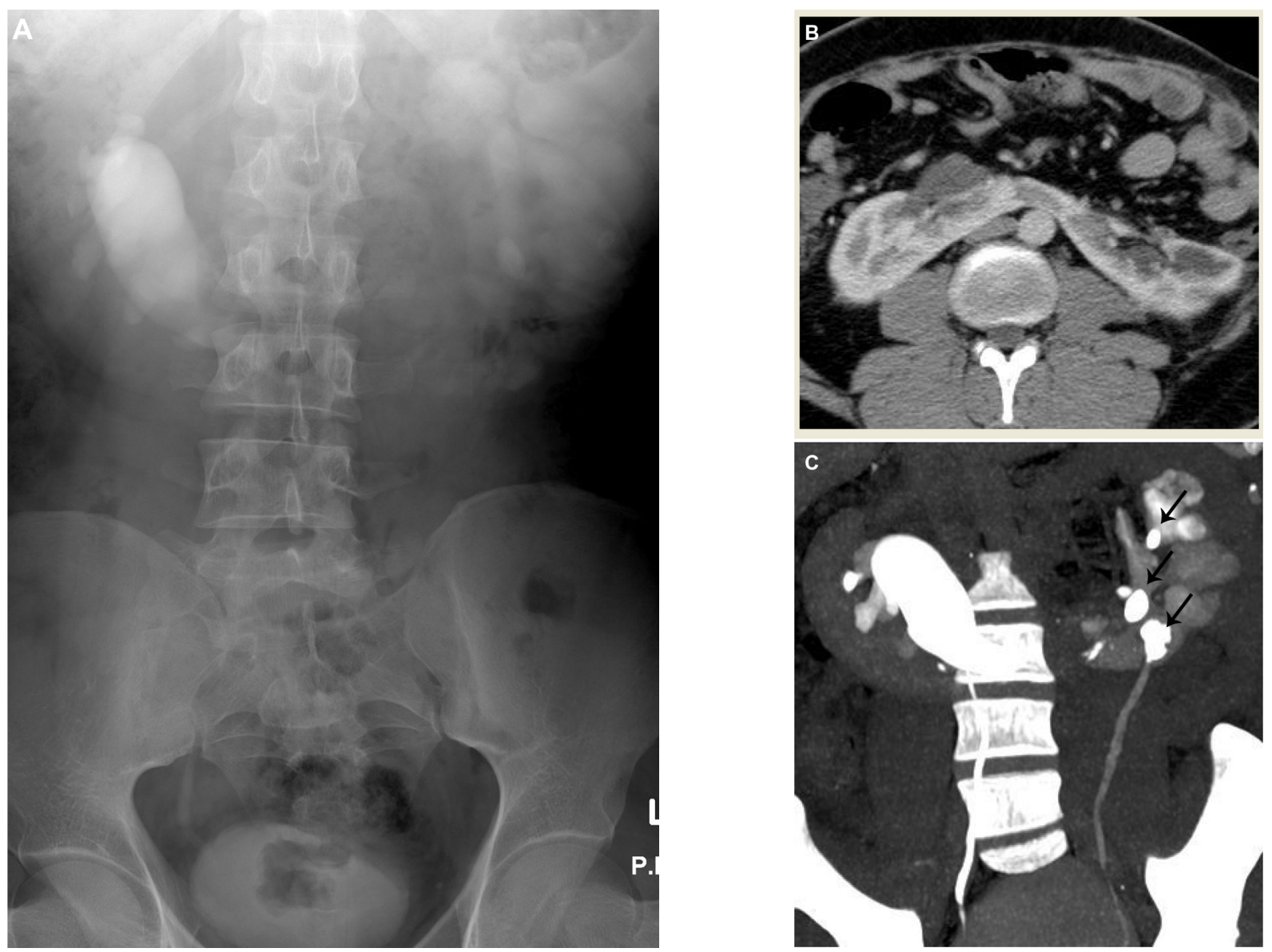

Figure 2 Horse shoe kidney. (A) Intravenous urography shows medialization of the longitudinal axis of the right compartment with dilated malrotated renal pelvis; the left kidney shows faint contrast excretion. (B) Axial contrast enhanced computed tomography shows the renal isthmus formed of enhancing renal parenchyma anterior to aorta and inferior vena cava; both compartments are malrotated with dilated right renal pelvis. (C) Computed tomography urography shows the horseshoe kidney with malrotated dilated right renal pelvis resulting from pelviureteral junction narrowing with multiple left renal stones (arrows) and hydronephrotic changes.

differentiate the abnormally enhancing renal tumors from the normal enhancing renal parenchyma with focal hypertrophy.

\section{Ureteropelvic junction obstruction}

IVU can detect the calyceal outline and the dilated renal pelvis if the dilatation is not severe enough to impair kidney function. Dalla Palma et al suggested that if we depend only on IVU, many upper urinary tract anomalies, including ureteropelvic junction obstruction, can be misdiagnosed. ${ }^{5}$ The absence of a dilated ureter distal to the renal pelvis suggests an obstruction at the ureteropelvic junction. ${ }^{6}$

Another problem with IVU is the presence of intestinal gases that make the diagnosis of urinary tract (UT) abnormalities challenging. CTU can overcome the problem of bowel preparation, as the density resolution at CTU is higher than in an X-ray, and it also can detect a minimal amount of contrast in cases of impaired renal function. CTU can also detect the location and cause of obstruction, and crossing vessels can be detected before surgery. ${ }^{7}$ CTU sensitivity in the diagnosis of obstruction is $100 \%$ in comparison with
$74 \%$ for IVU. CTU can be used as a "one-stop-shop" study for examination of cases of pelviureteral junction obstruction (Figure 3$).^{8}$

\section{Urolithiasis}

IVU was the procedure of choice for diagnosing urinary urolithiasis. In the last 2 decades, CT has replaced IVU in stone detection, especially in patients with renal colic. IVU can diagnose only radio-opaque stones. ${ }^{9}$

CTU can be used to diagnose renal stones, even radiolucent ones; it can help detect the stone's composition; and it is better than IVU in planning percutaneous nephrolithotomy. ${ }^{10}$

The presence of secondary signs of obstruction at CTU, such as hydronephrosis and perinephric stranding, has a $90 \%$ positive predictive value. ${ }^{11}$

\section{Tumors}

Diagnosis of renal masses using IVU has very low sensitivity, and once the mass is diagnosed, additional imaging is required 

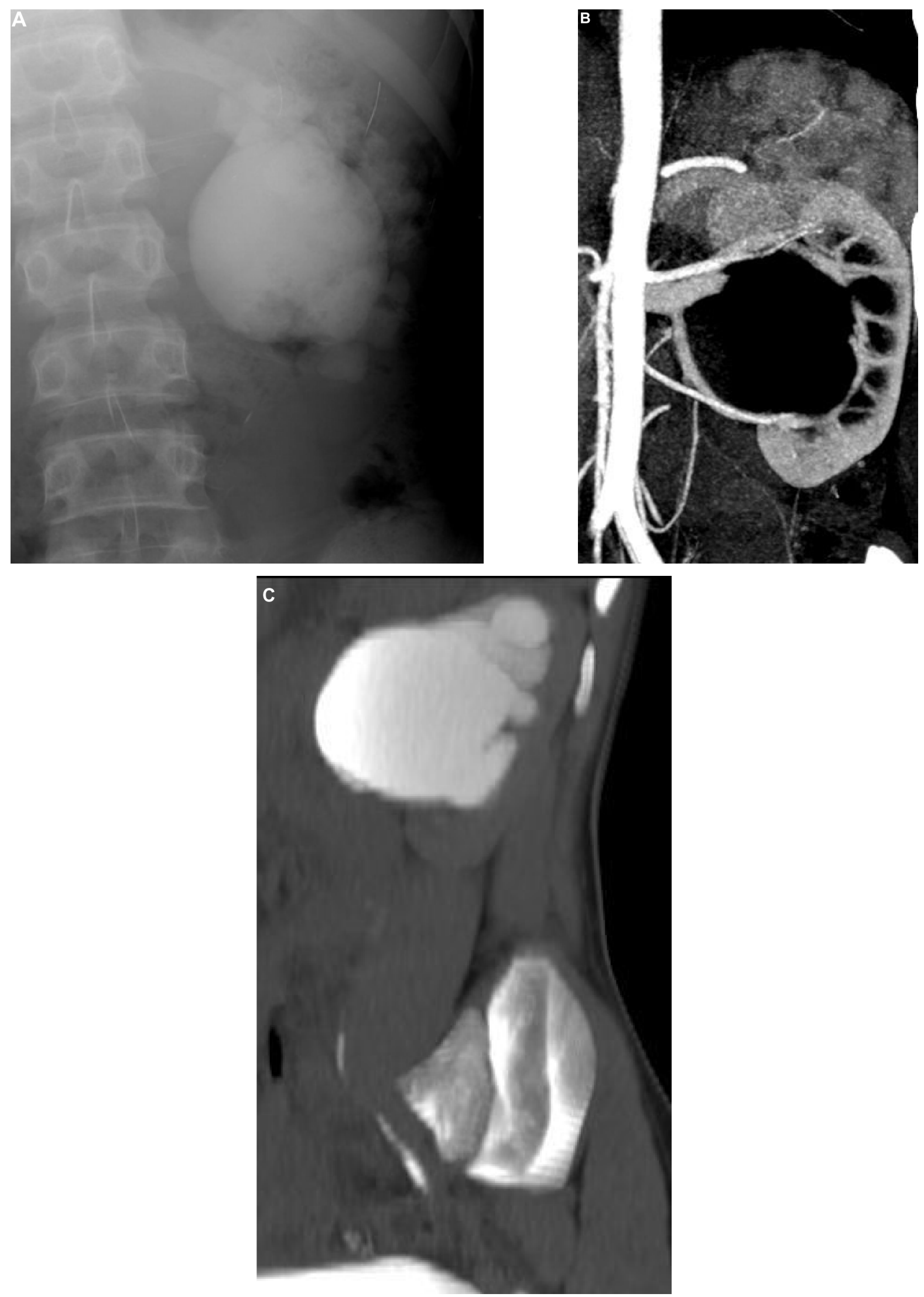

Figure 3 Left pelviureteral junction obstruction. (A) Intravenous urography shows hydronephrotic left kidney with ballooned extrarenal pelvis. (B) Computed tomography angiography shows crossing vessels at the left pelviureteral junction. (C) Sagittal reformatted computed tomography urography for the left kidney shows dilated calyces with ballooned extrarenal pelvis and narrowing at the pelviureteral junction; the left ureter is of normal caliber. 

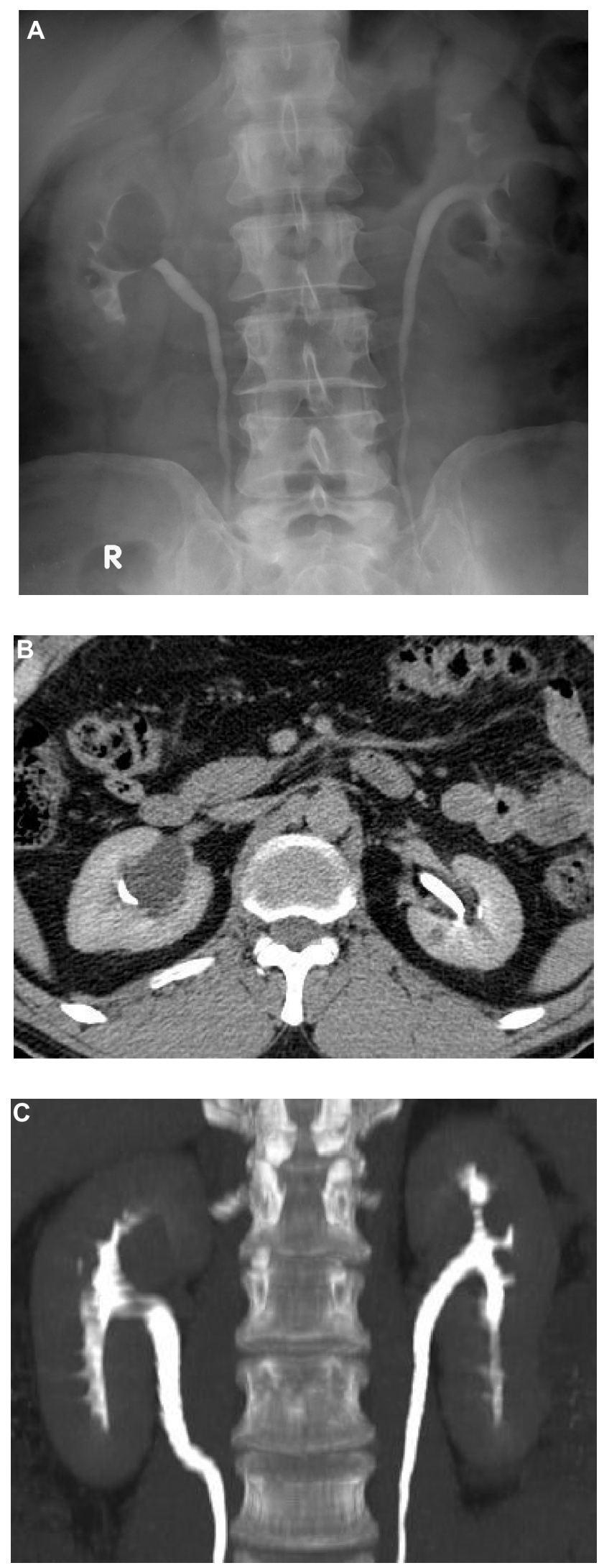

Figure 4 Right renal cyst. (A) Intravenous urography shows a lucent defect at the right upper pole displacing the calyces. (B and $\mathbf{C}$ ) Axial computed tomography and computed tomography urography show a right upper polar renal cyst displacing the upper calyces.
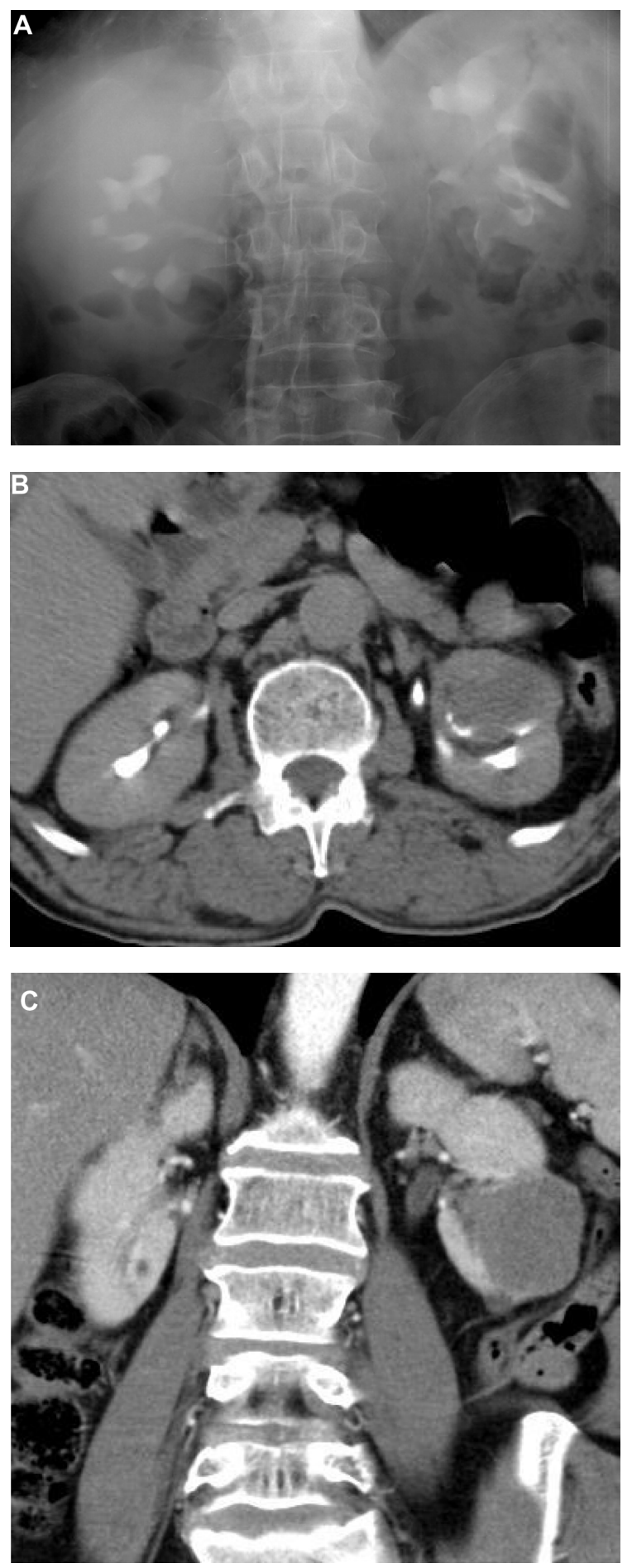

Figure $\mathbf{5}$ Left renal tumor. (A) Intravenous urography show a filling defect at the left lower calyx. (B and C) Axial and coronal contrast enhanced computed tomography shows a renal parenchymal tumor infiltrating the calyces.

for characterization and staging. ${ }^{3}$ As CTU replaces IVU in the investigation of patients with hematuria, the detection of renal cancer has increased. With CTU, the nephrographic phase is the most accurate for diagnosis and staging of the tumors. ${ }^{12,13}$ Unenhanced phase is important in diagnosing fat, 

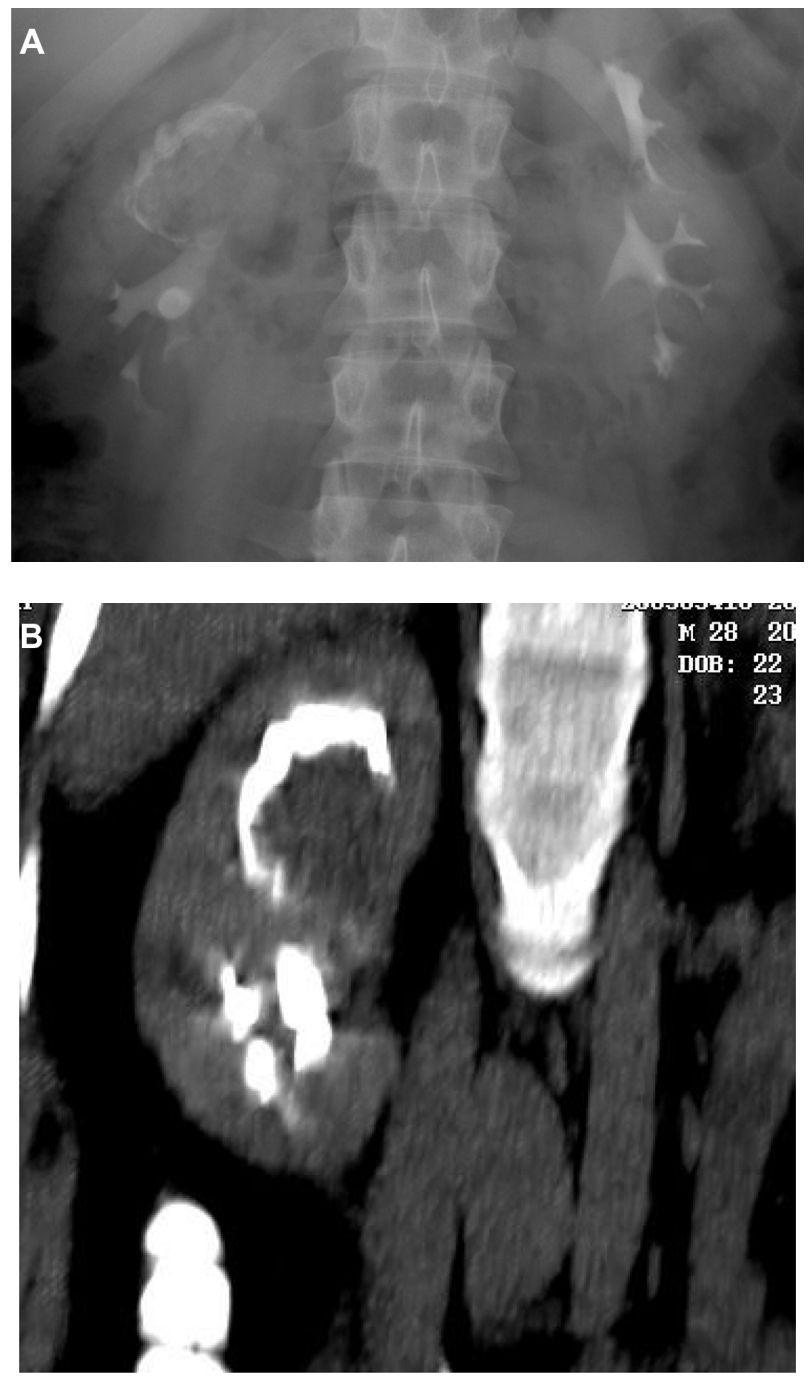

Figure 6 Right pelvicaliceal tumor. (A) Intravenous urography shows localized upper hydrocalycosis with filling defect inside. (B) Computed tomography urography shows soft tissue mass inside the upper calyx.

hemorrhage and calcification, whereas contrast-enhanced scans are important for surgical planning to detect exact tumor extension and anatomical relations and for vascular assessment that IVU cannot delineate ${ }^{14}$ (Figures 4-6). CTU can differentiate the subtypes of renal cell carcinoma, using the degree of enhancement, the enhancement pattern, calcifications, and tumor spread. ${ }^{15}$

A urothelial tumor appears, using IVU, as a filling defect inside the pelvicaliceal system, the ureter, or the bladder, whereas with CTU, it appears as either single or multiple filling defects. CTU can also detect focal thickening of the urinary tract, which can suggest the presence of a tumor. ${ }^{16}$ Small tumors can be missed using IVU, whereas CTU can detect small lesions equal to or smaller than $0.5 \mathrm{~cm} .{ }^{17} \mathrm{CTU}$ also is an accurate method for the detection of bladder cancer in patients with hematuria (Figure 7). ${ }^{18}$

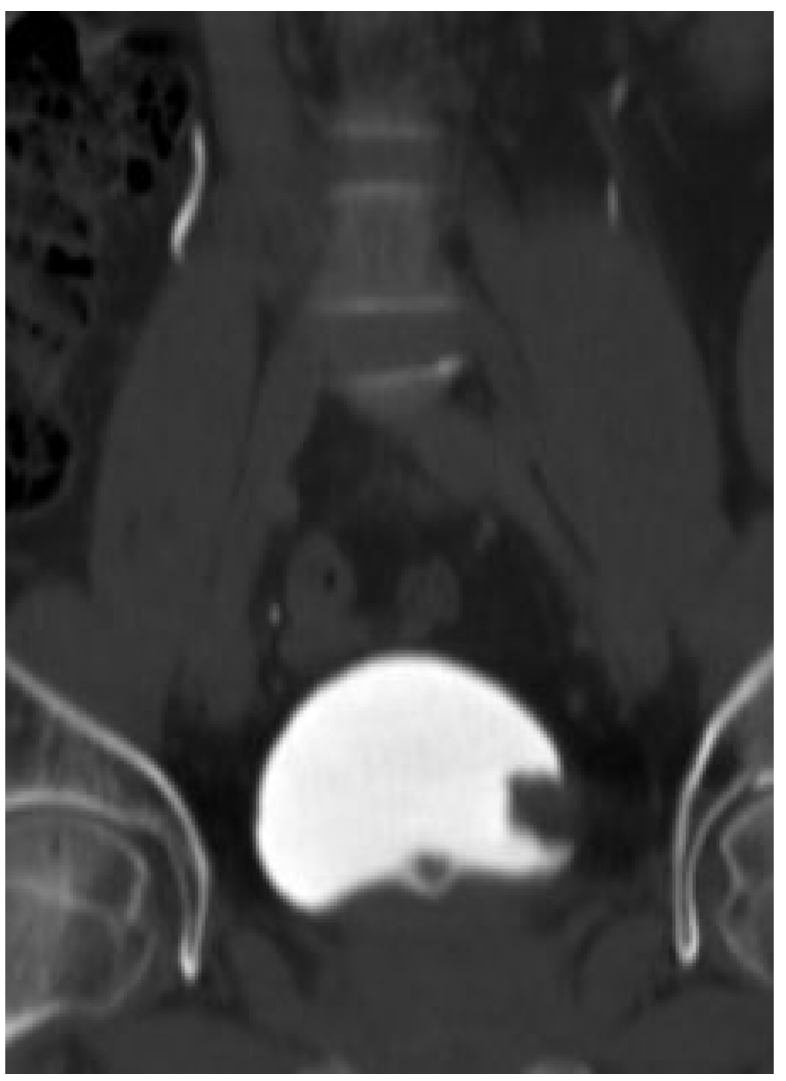

Figure 7 Bladder tumor. Computed tomography urography shows soft tissue tumor at the left bladder wall.

\section{Trauma}

IVU is of low yield in the evaluation of renal trauma. IVU can give an idea of hypo or nonfunctioning kidney, contrast extravasations, filling defect of blood clots in the pelvicaliceal system, and displacement of calyces. ${ }^{19}$ The CTU nephrographic phase provides information about kidney function, renal laceration, subcapsular hematoma, and the delayed excretory phase used for the detection of contrast extravasations.

CT can detect vascular injury at the early phases of CTU. Cortical rim sign at CT is evidence of renal artery occlusion, with subcapsular flow being preserved from the capsular artery without perfusion at the remaining parenchyma. Injury of the ureter may occur at the ureteropelvic junction and, with contrast extravasations, can be detected with IVU. ${ }^{20} \mathrm{CTU}$ is good for evaluating the ureter, and it can demonstrate the opacified normal ureter, while in extensive extravasations of contrast it is difficult to identify the opacified ureter. ${ }^{21}$

\section{Infection}

IVU was the primary imaging modality for diagnosing acute pyelonephritis (APN) in the past. Its role has diminished, and at this time, it plays a minor role in the imaging of patients 
with acute bacterial pyelonephritis. The only role for IVU these days is screening for obstruction, although this is now better performed by other imaging modalities. ${ }^{22,23}$ Among patients with APN, it is reported that IVU is positive only in one quarter of cases. Positive findings include diffuse enlargement of the affected kidney; delayed contrast excretion with dense persistent striated nephrogram, in some cases with delayed faint filling of the calyces; and that the collecting system may be dilated or effaced. ${ }^{24}$

The sensitivity of IVU is not enough to diagnose APN, and it also cannot characterize the type of parenchymal affection (cyst, tumor, or abscess), or demonstrate the complications. ${ }^{25,26}$

CT is considered the modality of choice either for diagnosis or follow-up of pyelonephritis, despite radiation exposure, the use of iodinated contrast, and its relatively high cost. It is a readily available and sensitive method for evaluating the extent of parenchymal infection, associated complications, and whether there is extrarenal involvement of other organs at the abdomen and pelvis. ${ }^{27}$

In some cases, if the diagnosis is not definite, a delayed CT scan for the kidney after 3 hours may be required to assess retention of contrast that differentiates APN from tumors and infarctions.

Nonenhanced CT scan of the abdomen and pelvis is used to evaluate the kidney size, areas of abnormal density (such as areas of hemorrhage, calcifications, stone, gas, masses, and abnormal fluid collection), and perinephric stranding. In case of APN, the involved areas may display low attenuation as a result of edema or necrosis; rarely in hemorrhagic bacterial nephritis the affected parenchyma display higher attenuation than normal parenchyma. ${ }^{25,28}$

Imaging of the kidneys at a nephrographic phase after contrast administration allows accurate detection of renal parenchymal infection and its actual extension. When using early-contrast enhanced CT in cases of APN, there is a loss of corticomedullary differentiation, with one or more wedge-shaped zones or streaky areas of lesser enhancement extending from the papilla in the medulla to the kidney capsule. The affected parenchyma may show homogeneous or heterogeneous enhancement, but it is less enhanced than normal parenchyma. ${ }^{29}$ This pattern of enhancement is a result of tubular obstruction caused by inflammatory debris within the lumen, interstitial edema, and vasospasm. ${ }^{30}$ There may be striated nephrogram, but it is not characteristic for APN, as it may occur in the normal kidney when low osmolar iodinated contrast is used in dehydrated patients. ${ }^{29}$ Early enhanced CT is highly sensitive in the detection of the involvement of the pelvicaliceal system, which shows a thickened enhancing wall that may be the only sign of ascending infection. It also depicts the extrarenal extension and the involvement of the Gerota's fascia, and the presence of nonenhancing fluid locules inside suggest fluid liquefaction and abscess formation. Diffuse renal involvement in cases of APN will lead to impaired kidney excretion of contrast in proportion to the severity of the infection. ${ }^{31}$ The sensitivity and specificity of CT in the diagnosis of acute pyelonephritis are estimated at $86.8 \%$ and $87.5 \%$, respectively. ${ }^{32}$

IVU is of limited use in the diagnosis of renal abscesses, as it can only demonstrate the findings of APN such as renal enlargement, delayed contrast excretion with dense persistent striated nephrogram, and delayed faint filling of the calyces. In cases of large abscesses, there is compression and displacement of the adjacent calyces, and the peripheral lesions may produce a contour bulge. The perirenal abscess may displace the kidney and mask the kidney outline if it reaches a considerable size. CT is the imaging study of choice for the diagnosis of renal and perirenal abscess. Using contrastenhanced CT, the abscess appears as round or geographic nonenhancing fluid collections with low-density fluid, but in the early stages, the fluid contents may have higher density than that of the clear uninfected fluid. The abscess may have an enhancing rim, representing a pseudocapsule with varied wall thicknesses and frequent nodularity. A halo of diminished enhancement may surround the abscess during the nephrographic phase. ${ }^{25}$ In rare cases, gas may be present within the abscess. The renal fascia is often thickened with soft-tissue stranding, and septal thickening and perinephric fat obliteration are commonly found. CT can detect extension into the psoas muscle, perirenal, anterior or posterior pararenal spaces, and the true pelvis.

In cases of emphysematous pyelonephritis, X-ray can detect the abnormal collection of gas at the renal fossa in $70 \%$ of patients. ${ }^{33} \mathrm{CTU}$ is the modality of choice and the most reliable and sensitive technique for evaluating patients with emphysematous pyelonephritis. The type of emphysematous pyelonephritis can be easily and accurately defined on the basis of CT findings, as CT can define the location of the gas and its extension. ${ }^{33} \mathrm{CT}$ findings include parenchyma enlargement and destruction, small bubbly or linear streaks of gas radiating from the papillae, gas-fluid levels, and focal tissue necrosis with or without renal and perirenal abscess. ${ }^{33,34}$

In cases of xanthogranulomatous pyelonephritis (XGP), the affected kidneys at IVU are usually enlarged and nonfunctioning. Stag-horn stone at the preliminary plain 
radiograph is seen in most of the cases. In some cases, there may be some opacification of the kidney and patchy or focal loss of nephrogram. Inflammatory extension to the perirenal space will obscure the kidney margins. CTU is the imaging modality of choice and is essential for preoperative assessment of XGP, as surgical planning depends on the accurate assessment of the extrarenal extent of disease, if any. The combination of a nonfunctioning enlarged kidney, a central calculus within a contracted renal pelvis, expansion of the calices, and inflammatory changes in the perinephric fat is strongly suggestive of XGP. Although the branching area of hypoattenuation (because of its lipid content) extending from the contracted renal pelvis may suggest hydronephrosis, the low attenuation corresponds to an extensive inflammatory infiltrate, rather than fluid, in almost all cases; it may be acalculous in $10 \%$ of cases. ${ }^{25}$

In chronic pyelonephritis, IVU was the modality of choice in the past but is less sensitive than $\mathrm{CT}$ in demonstrating chronic pyelonephritis and requires a functioning kidney to demonstrate calyceal change and contour irregularities. ${ }^{35}$ CTU demonstrates the calyces, pelvis, and ureter in detail, and the renal outlines also are usually well-defined.

In renal tuberculosis, IVU can detect the calcification, cavity, and infundibular stenosis that lead to focal (amputated calyx) or generalized hydronephrosis. ${ }^{23}$

CT clearly depicts the extension of the parenchyma disease as well the extrarenal spread. ${ }^{36,37} \mathrm{CT}$ is the most sensitive modality for identifying renal calcifications ${ }^{38}$ and can detect parenchyma thinning and scarring. Tuberculous granuloma is seen at CT with caseous material or calcification inside. Fibrotic strictures of the infundibula, renal pelvis, and ureters may be seen in contrast-enhanced CT and are highly suggestive of tuberculosis. ${ }^{36,37}$

\section{Discussion}

IVU has been widely used in diagnosing urological disease; nowadays, its role has diminished to the point that it is considered "dead" by many authors. ${ }^{1-4}$ IVU could show the integral configuration of the urinary system and the diseased region, such as the extent of dilatation of the calyces, renal pelvis, and ureter, and can give a global idea about renal function.

There are some disadvantages of IVU, including the bowel preparation, which is necessary. If the bowel preparation is not done well, the quality of the image is poor, and misdiagnosis can easily occur. In addition, the patient might feel uncomfortable when abdominal compression is used. In some patients, because of obstruction, renal function may be lost with nonvisualization of the kidney.
CTU is superior to IVU and is becoming the primary imaging method for evaluation of patients with hematuria and other genitourinary conditions. The major disadvantage of CT urography compared with excretory urography is the radiation exposure, with the doses of four-phase CT urography of about 25-35 mSv compared with a mean effective dose of $3.6 \mathrm{mSv}$ for excretory urography. There are, however, many variations in CTU protocols these days that are intended to reduce the radiation dose. Another minor concern is asymmetric excretion, particularly in those with unilateral obstruction. In these patients, the lack of sequential imaging with CT urography can result in suboptimal opacification of the obstructed side. Many experts agree that regardless of the CT urographic protocol used, there will always be ureteric segments that are suboptimally opacified and distended. ${ }^{39}$ There are concerns that urothelial lesions in unopacified segments might be missed because of these deficiencies. ${ }^{40}$ Tsili et al found that the finding of a nonopacified ureter had a negative predictive value of $100 \%$ for the presence of urothelial lesions. ${ }^{17}$

In conclusion, CTU currently has the upper hand over IVU in the diagnosis of different abnormalities of the urinary tract with high diagnostic accuracy; IVU does not have any diagnostic advantage over CTU in different complex urinary tract abnormalities. The future goal is to overcome the high radiation dose of the CTU by using low-dose protocols and split-dose techniques that provide more detailed information than that from IVU with a radiation dose comparable to that of IVU.

\section{Disclosure}

The authors report no conflicts of interest in this work.

\section{References}

1. Thomsen HS, Lindequist S, Brems-Dalgaard E. [Retirement plan for a 70-year-old. Intravenous urography disembarks from uroradiology]. Danish. Ugeskr Laeger. 2002;164(11):1484-1488.

2. Smith RC, Rosenfield AT, Choe KA, Essenmacher KR, Verga M, Glickman MG, Lange RC. Acute flank pain: comparison of non-contrast-enhanced CT and intravenous urography. Radiology. 1995; 194 : 789-794.

3. Franco A, Tomás M, Alonso-Burgos A. [Intravenous urography is died. Long live the computerized tomography!]. Spanish. Actas Urol Esp. 2010;34(9):764-774.

4. Laissy JP, Abecidan E, Karila-Cohen P, Ravery V, Schouman-Claeys E. [IVU: a test of the past without future?]. French. Prog Urol. 2001; 11(3):552-561.

5. Dalla Palma L, Morra A, Grotto M. CT-Urography. Italian. Radiol Med. 2005;110(3):170-178.

6. Tan BJ, Smith AD. Ureteropelvic junction obstruction repair: when, how, what? Curr Opin Urol. 2004;14(2):55-59.

7. Kawamoto S, Horton KM, Fishman EK. Computed tomography urography with 16-channel multidetector computed tomography: a pictorial review. J Comput Assist Tomogr. 2004;28(5):581-587. 
8. El-Nahas AR, Abou-El-Ghar M, Shoma AM, Eraky I, El-Kenawy MR, El-Kappany H. Role of multiphasic helical computed tomography in planning surgical treatment for pelvi-ureteric junction obstruction. BJU Int. 2004;94(4):582-587.

9. Jindal G, Ramchandani P. Acute flank pain secondary to urolithiasis: radiologic evaluation and alternate diagnoses. Radiol Clin North Am. 2007;45(3):395-410, vii.

10. Fielding JR, Silverman SG, Rubin GD. Helical CT of the urinary tract. AJR Am Roentgenol. 1999;172(5):1199-1206.

11. Fielding JR, Fox LA, Heller H, et al. Spiral CT in the evaluation of flank pain: overall accuracy and feature analysis. J Comput Assist Tomogr. 1997;21(4):635-638.

12. Einstein DM, Herts BR, Weaver R, Obuchowski N, Zepp R, Singer A. Evaluation of renal masses detected by excretory urography: cost-effectiveness of sonography versus CT. AJR Am J Roentgenol. 1995;164(2):371-375.

13. Lang EK, Macchia RJ, Thomas R, et al. Improved detection of renal pathologic features on multiphasic helical CT compared with IVU in patients presenting with microscopic hematuria. Urology. 2003;61(3):528-532.

14. Akbar SA, Mortele KJ, Baeyens K, Kekelidze M, Silverman SG Multidetector CT urography: techniques, clinical applications, and pitfalls. Semin Ultrasound CT MR. 2004;25(1):41-54.

15. Kim JK, Kim TK, Ahn HJ, Kim CS, Kim KR, Cho KS. Differentiation of subtypes of renal cell carcinoma on helical CT scans. AJR Am J Roentgenol. 2002;178(6):1499-1506.

16. Dillman JR, Caoili EM, Cohan RH. Multi-detector CT urography: a one-stop renal and urinary tract imaging modality. Abdom Imaging. 2007;32(4):519-529.

17. Tsili AC, Efremidis SC, Kalef-Ezra J, et al. Multi-detector row CT urography on a 16-row CT scanner in the evaluation of urothelial tumors. Eur Radiol. 2007;17(4):1046-1054.

18. Turney BW, Willatt JM, Nixon D, Crew JP, Cowan NC. Computed tomography urography for diagnosing bladder cancer. BJU Int. 2006;98(2):345-348.

19. Glazer GM, London SS. CT appearance of global renal infarction. J Comput Assist Tomogr. 1981;5(6):847-850.

20. Nuñez D Jr, Becerra JL, Fuentes D, Pagson S. Traumatic occlusion of the renal artery: helical CT diagnosis. AJR Am J Roentgenol. 1996;167(3):777-780.

21. Thompson IM, Latourette H, Montie JE, Ross G Jr. Results of non-operative management of blunt renal trauma. J Urol. 1977;118(4):522-524.

22. Webb JA. The role of imaging in adult acute urinary tract infection. Eur Radiol. 1997;(6):837-843.

23. Baumgarten DA, Baumgartner BR. Imaging and radiologic management of upper urinary tract infections. Urol Clin North Am. 1997;24(3):545-569.

24. Dunnick NR, Sandler CM, Newhouse JH, Amis ES. Textbook of Uroradiology. 3rd ed. Batimore, MD: Lippincott William \& Wilkins; 2011.
25. Craig WD, Wagner BJ, Travis MD. Pyelonephritis: radiologic-pathologic review. Radiographics. 2008;28(1):255-277.

26. Stunell H, Buckley O, Feeney J, Geoghegan T, Browne RF, Torreggiani WC. Imaging of acute pyelonephritis in the adult. Eur Radiol. 2007;17(7):1820-1828.

27. Lee JK, McClennan BL, Melson GL, Stanley RJ. Acute focal bacterial nephritis: emphasis on gray scale sonography and computed tomography. AJR Am Roentgenol. 1980;135(1):87-92.

28. Rigsby CM, Rosenfield AT, Glickman MG, Hodson J. Hemorrhagic focal bacterial nephritis: findings on gray-scale sonography and CT. AJR Am Roentgenol. 1986;146(6):1173-1177.

29. Blandino A, Mazziotti S, Ascenti G, Gaeta M. Acute renal infections. In: Quaia A, editor. Radiologic Imaging of the Kidney. Berlin, Germany: Springer; 2011:417-444. German.

30. Talner LB, Davidson AJ, Lebowitz RL, Dalla Palma L, Goldman SM. Acute pyelonephritis: can we agree on terminology? Radiology. 1994;192(2):297-305.

31. Stunell H, Buckley O, Feeney J, Geoghegan T, Browne RF, Torreggiani WC. Imaging of acute pyelonephritis in the adult. Eur Radiol. 2007;17(7): $1820-1828$

32. Majd M, Nussbaum Blask AR, Markle BM, et al. Acute pyelonephritis: comparison of diagnosis with 99 m-Tc DMSA, SPECT, spiral CT, MR imaging and power Doppler US in and experimental pig model. Radiology. 2001;218 (1):101-108.

33. Huang JJ, Tseng CC. Emphysematous pyelonephritis: clinicoradiological classification, management, prognosis, and pathogenesis. Arch Intern Med. 2000;160(6):797-805.

34. Hayes WS, Hartman DS, Sesterbenn IA. From the Archives of the AFIP. Xanthogranulomatous pyelonephritis. Radiographics. 1991;11(3): 485-498.

35. Hansson S, Dhamey M, Sigström O, et al. Dimercapto-succinic acid scintigraphy instead of voiding cystourethrography for infants with urinary tract infection. J Urol. 2004;172(3):1071-1073.

36. Hammond NA, Nikolaidis P, Miller FH. Infectious and inflammatory diseases of the kidney. Radiol Clin North Am. 2012;50(2): 259-270.

37. Verswijvel G, Janssens F, Vandevenne J, Stessens L, Meylaerts P, Palmers Y. Renal macronodular tuberculoma: CT and MR findings in an asymptomatic patient. JBR-BTR. 2002;85(4):203-205.

38. Jung YY, Kim JK, Cho KS. Genitourinary tuberculosis: comprehensive cross-sectional imaging. AJR Am J Roentgenol. 2005;184(1): $143-150$.

39. O’Connor OJ, Maher MM. CT urography. AJR Am J Roentgenol. 2010;195(5):W320-W324.

40. Nolte-Ernsting C, Cowan N. Understanding multislice CT urography techniques: Many roads lead to Rome. Eur Radiol. 2006;16(12) 2670-2686.
Reports in Medical Imaging

\section{Publish your work in this journal}

Reports in Medical Imaging is an international, peer-reviewed, open access journal publishing original research, reports, reviews and commentaries on all areas of medical imaging. The manuscript management system is completely online and includes a very quick and fair peer-review system, which is all easy to use.

\section{Dovepress}

Visit http://www.dovepress.com/testimonials.php to read real quotes from published authors. 